\title{
ARCHIVO
}

\section{El comercio de la madera en Madrid (primera mitad del siglo XVI)}

La Guia de Cuenca de Larrañaga, editada el año de 1929, menciona el transporte de la madera de sus ricos pinares por el primer tramo del curso de los ríos que bañan las tierras altas de Guadalajara y Cuenca, fundamentalmente el Tajo y su afluente el Guadiela, que con los ríos Ebro, Segura, Júcar y parte del Guadalquivir, se utilizaron con este fin. Son conocidos los profundos estudios sobre el tema de Julio Caro Baroja y otros, referidos en general a la navegación por el Ebro, pero no lo son tanto los párrafos de esta guía ni los que modernamente dedicó M. ${ }^{2}$ Luz Rokisky a la que se realizaba por el Júcar, para llevarla a Cuenca ${ }^{1}$.

En la investigación que se llevó a cabo en el Archivo de Protocolos de Madrid, de los años 1500 a 1540 aproximadamente, con el fin de localizar los artistas de las obras del plateresco madrileño, se encontraron otros varios documentos sobre este tema del transporte y comercio de la madera en las regiones de Castilla la Nueva, de gran interés en el campo de la construcción del siglo XVI. En algunos de ellos se describe la ruta seguida por la que se enviaba a Madrid por el Tajo, desde posiblemente Aranjuez y probablemente también desde Toledo, y las vicisitudes que en casos surgen debido al caudal variable de esta vía fluvial en su período torrencial, tal y como la describe la citada Guía de Larrañaga referida a los primeros años del siglo XX. Se da noticia de aquellos documentos por el interés que puedan presentar como testimonio de la pervivencia de un oficio, el de maderero, que tiene mucho de empresario u hombre de finanzas, y por las noticias que proporcionan sobre los protagonistas de esta actividad. Los documentos se dan en extracto e incluso incompletos en atención a este único objetivo y su

1 Julio Caro Baroja, Navarta. Las cuatro estaciones. Película documental. Larrañaga, Guía de Cuenca. (Cuenca, 1929). María Luz RoKISKI LAZARo, Arquitectura del siglo XVI en Cuenca. (Cuenca: Diputación, 1985). 
transcripción no es literal pues se modernizan los términos, y se traducen las abreviaturas aunque se conserva estrictamente la redacción.

En mapa adjunto se señalan los lugares mencionados en las escrituras transcritas aunque algunos no se han podido localizar, tales como Belbales, Fuensanta o Navaseca que por su mención junto a otros conocidos no plantean los problemas del lugar de Requena, que por el contexto del documento no parece referirse al pueblo actual levantino ${ }^{2}$.

MARGARITA ESTELLA

CSIC, Madrid

2 Pascual Madoz, Diccionario Geográfico-Estadístico-Histórico de España y sus posesiones de Ultramar (Madrid, 1845); Atlas... (Aguilar: Madrid, 1950). 


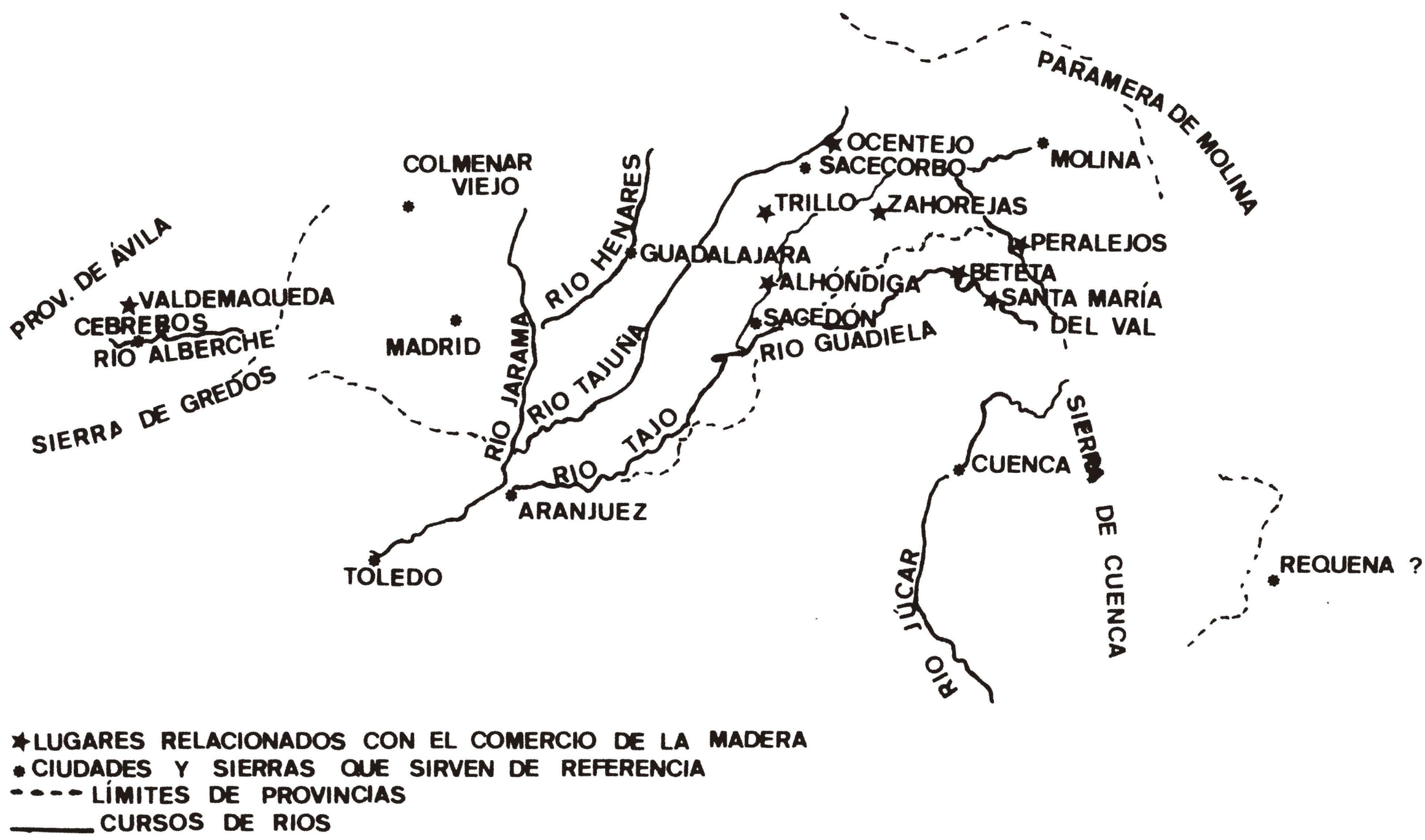


A.P.M. Diego Méndez, prot. n." 27, f." 598, 24 de febrero de 1520

Juan de Córdoba y otros se obligan a entregar maderos de los pinares de Valdemaqueda a Hernando Méndez en nombre de Tomás de Malmol? Medidas y precios.

En la villa de Madrid XXIIII [...] de febrero de DXX años, Juan de Córdoba vecino de la villa de Madrid y Francisco de Valladolid vecino de Robledo y Martín Velázquez vecino de Valdemaqueda todos tres de mancomún a voz de uno $[\ldots]$ se obligaron de. dar y pagar al $[\ldots]$ Secretario Tomás del Malmol [¿Marmol?] y a Hernando Méndez en su nombre que está presente, a saber ciento y cinco maderos de los pinares de Valdemaqueda, los ochenta de doce pies en largo y de tabla y cinco [...] que en su poder el dicho Juan de Córdoba $[\ldots]$ rubricado de mí el escribano y $[\ldots]$ queda en poder de Sillero, y otros veinticinco maderos de a siete pies en largo y el mismo [...] de los otros su precio de veintitrés maravedises cada madero $[\ldots]$ e asimismo recibieron los susodichos $[\ldots]$ y se obligaron de le dar traída y puesta en esta villa de aquí a fin del mes de mayo primero que viene $[\ldots]$, presentes Hernando Sillero $[\ldots]$

A.P.M. Rojas, prot. n." 86 , f." 580,6 de mayo de 1528

Se concierta Pedro del Moral, vecino de Ciempozuelos y Pedro Lorenzana sobre llevar madera desde la Negrilla de Albóndiga a Madrid. la cual Andrés Rebeco está obligado a dar al Obispo de Plasencia. Precios y medidas.

A VI de mayo de quinientos y veinte y ocho se concertaron Pedro del Moral vecino de Ciempozuelos y Pedro de Lorenzana en sobre llevar la madera desde la Negrilla de Alhóndiga a Madrid que está obligado a dar el señor Rebeco al Obispo de Plasencia mi señor, á de llevar sesenta y cinco vigas de media vara y tercia en canto y ha de ser el largo a treinta y cinco pies cada una de estas por un cargo /Item quinientas vigas de a veintidós pies en largo y si algunas tuvieren un pie más que no se le hayan de cortar, han de tener de marco cuarta y sesma y una pulgada más en canto y en tabla, estas quinientas vigas han de ir por cien cargas a cinco de ellas por cada cargo. Ytem mas otras trescientas vigas del mismo largo de veintidós pies y de tercia y cuarta, las cuales dichas trescientas vigas han de ir por cien cargos, tres vigas en cada cargo, lo cual ha de llevar para el día de San Juan primero que viene, cuarenta cargos, lo restante para en fin del mes de septiembre que viene que lo haya llevado con que se han de dar treinta ducados el día que hiciere la obligación y se ha de quitar de ellas la tercia parte de lo que se llevare de aquí el día de San Juan y la resta en lo que se llevare después, obligáronse los sobre dichos de cumplir y guardar lo sobre dicho y de hacer la obligación en forma y porque no sabía firmar rogó al Señor Andrés Rebeco que lo firmase por él, testigos que fueron presentes Bartolomé Moreno y García de Alcocer y Francisco 
Sanches vecino de Benavent? fecha $[\ldots]$ a ruego del dicho pedro del Monte y por testigo |... .-Firma Andrés Rebeco ante Rojas y Pedro Lorenzana.

A.P.M. Diego Méndez, prot. n." 37, f." 628, 30 agosto 1533.

Cebrián de la Cruz, vecino de Madrid, da poder a Mateo de Hita para resarcir de los daños causados por la madera que desde las sierras de Cuenca y Molina traía por el Tajo, que se desbordó por la corriente.

Sepan cuantos esta carta de poder vieren como yo Cebrián de la Cruz, vecino de la villa de Madrid digo que por cuanto yo traía por el río Tajo cierta madera de las sierras de Cuenca y Molina y con la corriente que hubo en el dicho Río se desbarató la dicha madera con la madera de muchos otros que traía a cargo Pedro de Lázaro vecino de Trillo e otros sus ausentes la cual está perdida? en la parte que corre ha hecho daños por ende otorgo y conozco que doy y otorgo todo mi poder cumplido $|\ldots|$ a vos Mateo de Hita vecino de Madrid especialmente para que en mi nombre podáis tomar cualquier asiento y concierto a cualesquier persona que recibió daño en su hacienda con las dichas maderas y obligar y obliguéis a mí y a mis bienes a complir y pagar los maravedies de los tales asientus de la forma y manera y a los plazos $|\ldots|$ y recibáis y cobréis la dicha madera mía donde quiera que la halláreis y deis carta de pago de ello $|\ldots|$ y la madera que de Toledo abajo se hallare mía darse a las personas $|\ldots|$ e recibir los tales dineros, $[\ldots]$ cartas de pago de ello $[\ldots]$ otorgo a vos el dicho Mateo de Hita $|\ldots|$ que fue fecha [... en la villa de Madrid a treinta días del mes de agosto año de mil quinientos y treinta y tres años.

A.P.M. Gabriel Hernández, prot. n." 52, f." 421;424, 4 de septiembre de 1534.

El carpintero Francisco de Miranda traspasa el poder que tenía del maderero Andrés Rebeco para cobrarle entre otras cosas la madera que habia llevado por el Tajo desde Ocentejo a Toledo, al Procurador de causas Juan de León.

Sepan cuantos esta carte de poder y sustitución vieren cómo yo Francisco de Miranda carpintero vecino de la villa de Madrid en nombre y por virtud del poder que tengo signado de Hernán Sánchez escribano público de ella de Andrés Rebeco vecino de esta villa su tenor del cual es este que sigue: Sepan cuantos esta carta de poder vieren cómo yo Andrés Rebeco, maderero, vecino de la villa de Madrid, otorgo y conozco que doy y otorgo todo mi poder cumplido $|\ldots|$ y más cumplidamente de derecho lo puedo dar y otorgar de derecho y más puede valer a vos Francisco de Miranda, carpintero, vecino de la dicha villa de Madrid que estais ausente, bien así como si fueseis presente, especialmente para que por mí y en mi nombre y para mí mismo podáis pedir y demandar recibir y haber y cobrar todos y cualesquier maravedís que a mí me sean debidos, así por contratos como por conocimientos y alvalaes? o en otra cualquier manera, así de madera $[\ldots]$ como de trigo y cebada y de otras cualesquier cosas que me sean debidas por cualesquier persona o personas de cualquier estado y condición $[\ldots]$ y para que por mí y en mi nombre podáis cobrar y cobréis toda la madera que me falta de las maderas que yo he traído por el río Tajo de Ocentejo abajo hasta la muy noble ciudad de Toledo e lo que allí abajo me ha llevado el río o me hayan embargado o hurtado o se me haya quedado perdido o me lo hayan llevado en cualquier manera y por cualquier razón y para que sobre lo que así me hayan llevado o hurtado contra mi voluntad podáis dar y deis cualesquier [...] queja de la persona o personas que lo hayan llevado y lo seguir hasta llevar a debida justicia y ejecución y para que os podáis apartar y apartéis [...] de cualesquier queja o quejas que en mi nombre diéreis y para que de lo así demandáreis 
e diéreis y recibiéreis y cobráredes en mi nombre, podáis dar y otorgar $[\ldots]$ cartas de libre y finiquito las cuales valgan $[. .$.$] Otrosí doy este dicho poder para que la madera$ que yo cobrare y yo tuviera en cualesquier partes que yo la tenga podáis vender y vendáis así aserrado como por aserrar en poca cantidad o en mucha, mal vendida o bien vendida [...] y podáis cobrar los dichos maravedises que así montaren lo que así vendiéreis [...] Otrosí doy el dicho poder cumplido generalmente para en todos mis pleitos y causas. [...] otorgué esta carta de poder ante el escribano y notario público y testigos yusoescritos y la firmé de mi nombre $[\ldots]$ que fue fecha y otrogada $[\ldots]$ a cuatro días del mes de agosto de mil y quinientos y treinta y tres años, testigos [...] Pedro Gómez de Montalván criado del dicho Andrés Rebeco [...] Por ende por virtud del dicho poder [...] otorgo que en mi lugar $[\ldots]$ sostituyo a vos Juan de León $[\ldots]$ a cuatro $[\ldots]$ septiembre $[\ldots]$ mil quinientos treinta y cuatro.

A.H.P. Madrid, prot. n" 30, f." 669, 669 v', 10 de junio de 1536.

En relación a la Compañáa que se bizo entre el Licenciado Juan de Salmerón, su bermano Fernando Salmerón y Mateo de Hita para comerciar madera, se aclaran algunas de sus cláusulas referentes al aprovechamiento de parte de la madera para la edificación de sus casas, la forma de tomar cuentas a Hita y de la obligación de éste de no negociar otra madera que la que beneficie a dicha Compañia.

Nos el Licenciado Juan de Salmerón y el Contador Fernando de Salmerón decimos que por cuanto en la escritura de contratación que está entre nosotros y Mateo de Hita en razón de la madera que ha de comprar de los ducados que le tenemos dados y hemos de dar que pasó ante Diego Méndez escribano de la villa de Madrid, entre otras cláusulas está una que dice que cada una de las partes pueda sacar de la dicha madera después de sacada del agua la que de ella huviere menester para la labor y edificio de sus casas, y porque podría que si alguna de las dichas partes o quien por ellos lo hubiere de haber quisiera sacar tanta madera para sus casas por virtud de la dicha condición que fuese con daño y notable pérdida de las otras partes que por tanto queriéndolo el dicho Mateo de Hita tenemos por bien que yo el dicho Licenciado saque por virtud de la dicha condición hasta once mil maravedises al empleo y costas de la dicha madera después de sacada del agua, conforme a la dicha condición, y yo el dicho Contador pueda sacar hasta cuantía de diez mil maravedises por que yo no pongo casas ni quiero la dicha madera como el dicho Señor Licenciado con tanto que las dichas cantidades nos podamos dar el uno al otro y el otro al otro siendo para la labor de nuestras propias casas conforme a la dicha contratación y el dicho Mateo de Hita pueda sacar conforme a la dicha contratación hasta otros diez mil maravedises. Yten decimos que por cuanto en la dicha contratación está otra cláusula en que dice que el dicho Mateo de Hita está obligado a dar cuenta con pago cada vez que por nos o cualquiera de nos le fuere pedida que no se entiende por qué se le pida la tal cuenta o cuentas, que se ha de deshacer la compañía hasta que el dicho Mateo de Hita haya dispuesto? de todo el principal empleo que hubiere hecho en la compra de la dicha madera con tanto que el dicho Mateo de Hita [¿resida? 7 en el beneficiar de la dicha hacienda todo el tiempo que fuere necesario o conviniere al provecho y recibido de la dicha hacienda y a disponer de ella sin dar lugar a que por su ausencia haya más dilación en el disponer de la dicha hacienda conforme a la dicha contratación de la que convenga al provecho de ella porque si el dicho Mateo de Hita por muerte y por otro justo impedimento no pudiere entender en la dicha contratación hasta fenescerla que sea en mano de nos los dichos Licenciado y Contador apartar la dicha Compañía si quisiéremos. Ytem es condición entre las partes que el dicho Mateo de Hita durante la dicha Compañía que no entienda en otra con- 
tratación alguna de compra ni venta de madera suya ni ajena ni mucha ni poca cantidad salvo en las compras y ventas que fueren necesaria y tocantes a la dicha Compañía y firmamos lo de nuestros nombres fecha en la villa de Colmenar Viejo a siete días del mes de junio de mil y quinientos y treinta y seis años. En la villa de Madrid a diez días del mes de junio año de mil y quinientos y treinta y seis años. El Señor Licenciado Fernando de Salmerón.

A.P.M. Gabriel Hernández, prot. n." 64, f." 295-295 v.', 4 marzo 1537.

El Convento de San Jerónimo de Madrid da poder a Pedro de Orduña para cortar 700 pinos de los 2.000 pinos de la Sierra de Cuenca y debesa de Sierra Molina que la Emperatriz les habia dado de limosna y los otros 3.000 pinos que les bizo merced su Majestad. Revocan el poder que habian dado a Pedro Lázaro.

Sepan cuantos esta carta de poder vieren cómo nos el prior, frailes y convento del Monasterio del Señor San Jerónimo el Real Extramuros de la villa de Madrid, estando juntos $[\ldots]$ otorgamos y conocemos por esta presente carta que damos y otorgamos todo nuestro poder cumplido [...] a vos Pedro de Orduña vecino de la dicha villa de Madrid que estáis presente $[\ldots]$ especialmente para que por nosotros en nombre del dicho Monasterio vayáis a la sierra de Cuenca y a la dehesa de Sierra Molina y podáis cortar y cortéis y hacer cortar setecientos pinos que nos restan de cobrar de los dos mil pinos que su Majestad la Emperatriz nuestra Señora hizo merced y limosna a este dicho Monasterio y de trescientos pinos en la villa de Molina asimismo hizo merced y limosna al dicho monasterio [...] y asimismo podáis cortar y cortéis y hacer cortar los otros tres mil pinos que su Majestad hizo merced y limosna al dicho Monasterio para sus obras, en la dicha Sierra de Cuenca lo cual todo lo que dicho es podáis cortar y cortéis y hacer cortar y lo demandar, recibir e cobrar $[\ldots]$ y prometemos y nos obligamos $[\ldots]$ cuanto vos el dicho Pedro de Orduña [...] que fue fecha y otorgada esta carta de por ante mí el escribano público y testigos yusoescritos [...] en la villa de Madrid a cuatro días de marzo año del nascimiento de nuestro Salvador Jesucristo de mil y quinientos y treinta y siete [...], presente Andrés de Cueva mayordomo del dicho Monasterio [...] y Cristóbal de Salamanca sastre [...]. Otrosí nos los dichos Prior y frailes del dicho Monasterio decimos que por razón que nosotros tenemos dado para cortar y cobrar los dichos pinos nuestro poder cumplido a otras veinte personas y especialmente habemos dado y dimos poder a Pedro de Lázaro y a Pedro Berzas vecinos de Trillo para lo cobrar y cortar [...] por tanto decimos que revocamos y damos por ningunos todos los dichos poderes que hayamos dado.

A.P.M. Hernán Sánchez, prot. n." 14, sin foliar en parte, 15 de enero de 1538.

Andrés Rebeco y sus fiadores al no haber podido cumplir la obligación de entregar en el plazo acordado una cantidad de madera para el Obispo de Plasencia, renuevan la obligación.

Sepan cuantos esta carta de obligación vieren cómo yo Andrés Rebeco vecino de la villa de Madrid como principal deudor y Diego Fernández [...] y Mary Gómez su mujer con licencia [...], por ende yo el dicho Andrés Rebeco y Diego Fernández y Mary Gómez su mujer y Juan Alonso de Badillo y Francisco de Miranda carpintero y Francisco de la Vega carpintero, vecinos de esta villa como fiadores del dicho Andrés Rebeco y principales pagadores todos de mancomún $[\ldots]$ y decimos que por cuanto nos los susodichos éramos obligados a dar y pagar al Ilmo. Señor D. Gutierre de Carvajal Obispo de Plasencia cierta madera según se contiene en una obligación $[\ldots]$, la cual madera $[\ldots]$ trescientos y 
cuarenta y seis machones a veinte y dos pies de largo [...] a plazos ya pasados y por no tener los dichos machones nos convenimos y concertamos con Pedro de Lorenzana camarero y criado del dicho Señor Obispo en su nombre de dar y pagar al dicho Señor Obispo y a quien por el lo hubiere de haber por razón de los dichos trescientos y cuarenta y seis machones la madera siguiente: Seiscientas medias vigas de a cuarta [...] y una pulgada más en canto y otra en tabla [...] Item setecientas y treinta y ocho vigas de a tercia y cuarta de a veinte y dos pies de largo, lo cual todo hemos de dar y daremos aserrado y apilado en Alhóndiga, bajo de la puente, de los marcos e pies susodichos toda la dicha madera [...] a vista y contentamiento de Luis Ponce, alarife de esta villa de Madrid la cual dicha madera tenemos y nos obligamos de dar y entregar las dichas seiscientas $[\ldots]$ e las otras setecientas y treinta y ocho vigas para en fin del mes de mayo de este presente año con que se nos ha de dar y pagar la mitad de lo que montare el asierro luego que se acabare de aserrar la mitad de la dicha madera y la otra mitad luego que estuviera toda acabada de aserrar esto a precio de quince maravedises cada hilo $[¿$ ? $\}$ de asierro contando dos maderos por un hilo y que por esta obligación no se entienda que se innova en cosa alguna a la demás madera contenida en la dicha obligación que assí paso [...] en cuanto toca a los dichos trescientos y cuarenta y seis machones los cuales [...] en la madera susodicha y en lo demás la dicha obligación se queda en su fuerza y vigor y que por esta no sea visto ninguna de las partes alterar ni innovar la dicha obligación y nos obligamos de pagar [...] e los dichos [...]Andrés Rebeco $[\ldots]$ otorgamos esta carta $[\ldots]$ en la villa de Madrid a quince días del mes de enero del año de mil y quinientos y treinta y ocho años.

A.P.M. Hernán Sánchez, prot. n." 104, f." 120-121 v. ${ }^{4}, 16$ de enero de 1538.

En relación a la Compañía que se hizo entre el Licenciado Juan de Salmerón y el Contador Fernando de Salmerón, su hermano, con Mateo de Hita, para el comercio de la madera. se ajustan cuentas del dinero entregado por los primeros a Hita. Se citan sólo párrafos sobre el aprovisionamiento, compra y almacenamiento de la madera.

En la noble villa de Madrid a diez y seis días del mes de enero del nascimiento de nuestro Salvador Jesucristo de mil y quinientos treinta y ocho años en presencia de mí Hernán Sánchez escribano público de la dicha villa y de los testigos yusoescritos, los Señores Licenciado Juan de Salmerón y Contador Hernando de Salmerón su hermano asimismo de la dicha villa de Madrid de una parte, y Mateo de Hita carpintero asimismo vecino de la dicha villa de Madrid de la otra, dijeron que por cuanto ellos han tenido y tienen cierta compañía y contratación de madera en esta manera: Que los dichos Licenciado Juan de Salmerón y Contador Hernando Salmerón dieron al dicho Mateo de Hita mucha cantidad de dineros en veces para que el dicho Mateo de Hita fuese a las sierras de Cuenca y Molina e los emplease en madera como le paresciere y que traída la dicha madera la vendiera y granjeara el dicho Mateo de Hita sacando primeramente los dichos Licenciado Juan de Salmerón y Contador Hernando de Salmerón la madera que hubiesen menester en cierta cantidad y que la ganancia y pérdida que en la dicha madera oviese fuese de por medio, y las costas [...] que todo lo susodicho más largo paso en la dicha contratación que entre ellos se hizo [...] ante Diego Méndez escribano [...] en virtud de lo cual el dicho Mateo de Hita rescibió de los dichos [...] ochocientos ducados de cada uno de ellos [...] de los cuales dineros el dicho Mateo de Hita ha hecho ciertas compras de madera, así en Trillo donde hizo cierta compra de madera el año pasado $[\ldots]$ que ha hecho aserrar $[\ldots]$ y así la tiene vendida en las sierras de Cuenca y Molina donde compró e hizo otra maderada que tiene traída y sacada en la ribera del Tajo, en Requena [?] y Veguilla de Alhóndiga de más de dos mil piezas de madera 
labrada e polida $[\ldots]$ agora ellos se an concertado e convenido entre si que el dicho Mateo de Hita vuelva a los dichos Contador e Licenciado los dichos dineros que así le tienen dado para la dicha madera en esta manera [...], por ende el dicho Mateo de Hita [...] y Ana López su mujer $[\ldots]$ se obligaron a dar y pagar a los $|\ldots|$ Salmerón los dichos ochocientos ducados de oro a cualquiera de ellos y de dar y pagar en madera lo que el dicho Mateo de Hita paresciere en su conciencia...

A.P.M. Riaño, prot. n." 136, f." 236, 10 de marzo de 1540 .

Carta de poder de Pedro de Orduña, maderero, para Juan de ¿Ayarca?, de la merindad de Durango presente en Madrid. para cobrar a unos vizcainos vecinos de Zaborejas 10 que le deben por una escritura que pasó ante el escribano de Trillo. Testigos Cebrián de la Cruz, carpintero y Bartolomé de Vega y Francisco de San Juan. En Mudrid. a diez días de marzo de 1540.

A.P.M. Riaño, prot. n." $136,212 \mathrm{v} .213,10$ de abril de 1540.

Juan de Ayarca, vecino de Ayarca merindad de Durango, se obliga a Pedro de Orduña maderero a que de las doscientas piezas que él tiene en Belbales, tierra de Beteta, seña. ladas de la señal de Pedro de Orduña, dejará libres y desembargadas le? una cantidad de vigas puestas al tumbo del agua de la serrería de Peralejos abajo.

En la noble villa de Madrid a diez días del mes de abril de mil y quinientos y cuarenta por ante mí el escribano público y testigos yusoescritos Juan de Ayarca vecino de Ayarca de la merindad de Durango, dijo que se obligaba y obligó de las doscientas y tantas piezas que él tiene en Belbales, tierra de Beteta, que están señaladas de la señal de Pedo Orduña, maderero, vecino de esta villa, dejará libres y desembargadas en el astillero en el dicho valle a el dicho Pedro de Orduña cien vigas las cuales el dicho Pedro de Orduña ha de tomar en esta manera $[\ldots]$ en la dicha maderada por la parte que él quisiere tomarlas $[\ldots]$ hasta haber tomado las dichas cien vigas con que todas las que han de tomar han de ser de a treinta pies en largo arriba cada una y de palmo y medio arriba cada una de marco y aunque más largo y marco tuvieren las dichas vigas [...] que las pueda tomar el dicho Orduña, las cuales le da y dará por el precio y cuantía de ocho mil y quinientos maravedises, las cuales vigas ha de tomar el dicho Orduña o quien su poder hubiera [...] los cuales ocho mil y quinientos maravedises que le han de pagar en esta manera [...] Otrosí se obligó de dar al dicho Orduña otras treinta vigas de a treinta y cinco pies en largo y palmo y medio en canto y media vara en tabla, las cuales dará a precio de siete reales cada una, puestas a el tumbo del agua de la serrería de Peralejos abajo, las cuales dará fechas $[\ldots]$ el día $[\ldots]$ que las tiene labradas y la otra mitad [...] además de lo susodicho se obligó [...]. Otrosí se obligó que luego [...] dará y entregará al dicho Pedro de Orduña una licencia [¿?] que le entrego de Luis Carrillo para cortar en la dehesa de Belbales cuatrocientos pinos y en defecto de no darla le pagará al el dicho Pedro de Orduña cuatrocientos reales de plata castellanos. El dicho Pedro de Orduña que estaba presente [...] se obligó a pagar todas las cuantías de maravedises [...] e para lo cumplir e pagar ambas partes $[\ldots\}$ obligaron sus personas e bienes muebles y raíces [...], testigos Cebrián de la Cruz carpintero y Francisco de San Juan y Bartolomé de Vega. 
A.P.M. Méndez, prot. n." 37, f." 592v.'-593, 24 de julio de 1543.

Mateo de Hita, vecino de Madrid, se obliga a entregar a Luis Sillero, carpintero, vecino de Madrid, 100 vigas en el término de Zaorejas, puestas al tumbo del agua, a contento de los gancheros. Si no cumpliera, Luis Sillero podría escogerlas en el pinar de Mateo de Hita. Se especifica que se marquen con la señal del Sr. Obispo y se establecen lor plazos de entrega que podrán adelantarse si pasan antes los gancheros.

En la villa de Madrid a veinte y cuatro días del mes de julio año de mil y quinientos y cuarenta y tres años, Mateo de Hita vecino de Madrid otorgó que vendía y vendió y se obligaba y obligó de dar a Luis Sillero, carpintero vecino de Madrid, cien vigas de treinta y cinco pies de largo, medio pie más o menos, y de media vara en tabla y de tercia en canto, puestas en el término de Zahorejas, del Obispado de Cuenca, puestas al tumbo del agua a uso de madereros desde donde dizen la Fuensanta hasta la rastra de Navaseca, y si las dichas vigas estuvieren mal puestas al tumbo del agua que el dicho Mateo de Hita las pondrá bien a contento de los gancheros lo cual se obligó a dar $|\ldots|$ en fin de marzo primero del año de quinientos y cuarenta y cuatro y si antes pasaren los gancheros que entonces sea obligado a lo dar y pagará el día de San Miguel primero, se obligaba a tener hechas las dichas vigas e si no las tuviere hechas que el dicho Luis Sillero entre y pueda entrar en el pinar del dicho Mateo de Hita y las haga aderezar y hacer, escogiéndolas a vista de Hita y a su daño y aprovecho del dicho Luis Siller's, todo lo cual se obligó a dar por precio cada viga de once reales y medio pagados en esta manera: los sesenta $|\ldots|$ y la resta acabadas de hacer las dichas vigas, las cuales vigas se obligó el dicho Mateo de Hita de dar al dicho término buenas y sanas a esquina viva y cuadradas del marco susodicho al tumbo del agua como dicho es y si algina xema [?] hubiere en ellas que se pueda cofrir [?], que el dicho Luis Sillero sea obligado a las recibir y porque son para el señor Obispo de Plasencia que a costa del dicho Luis Sillero se eche el marco y señal que se echa a las otras maderas del dicho señor Obispo, lo cual se obligó el dicho Mateo de Hita de la forma y manera susodicha de lo dar, sopena que a costa del dicho Mateo de Hita el dicho Luis Sillero lo pueda comprar a los mayores precios. 


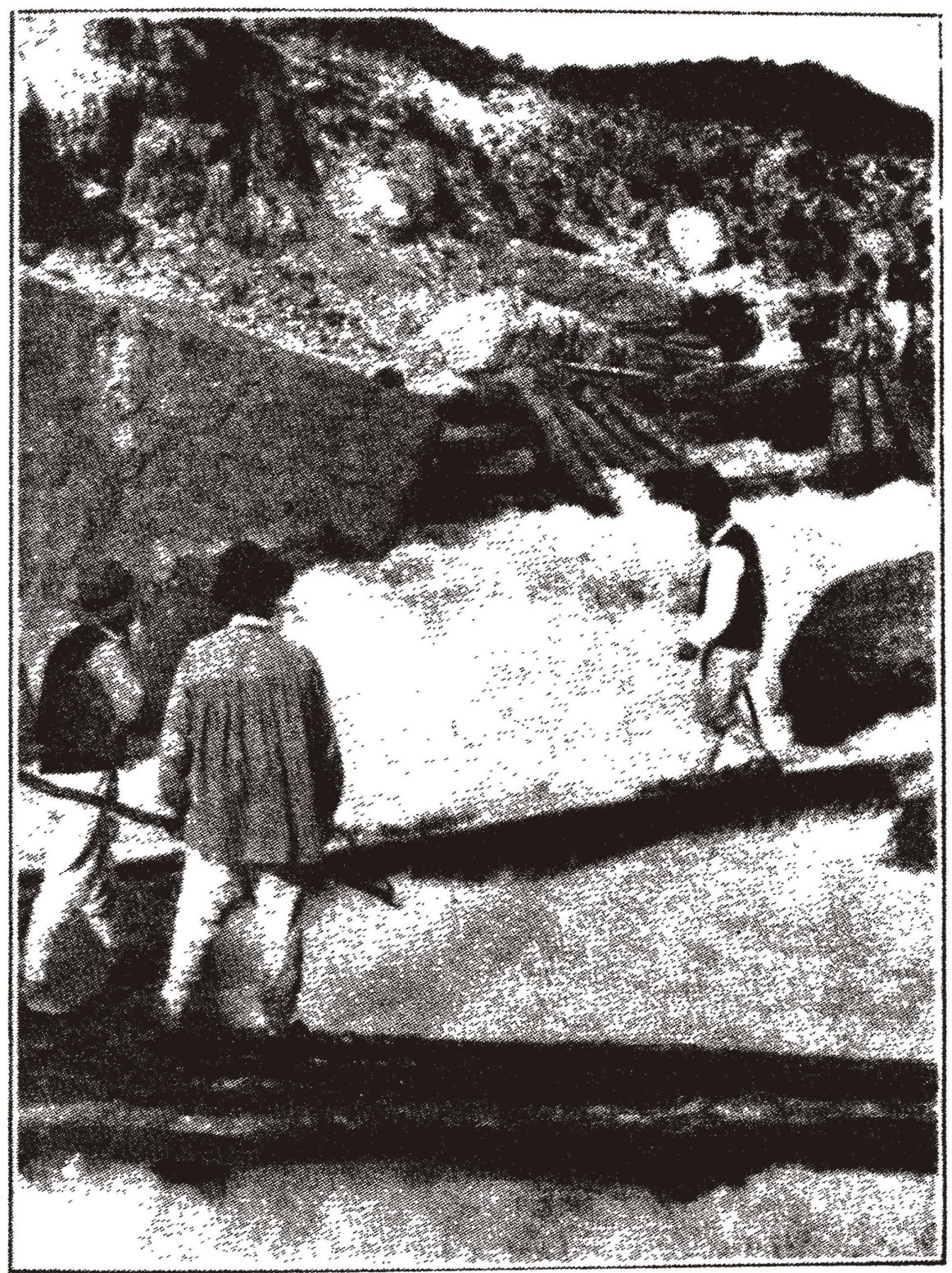

Lám. I.-Gancheros preparados para encauzar las piezas (de la Guía de Cuenca de la rrañaga, 1929). 


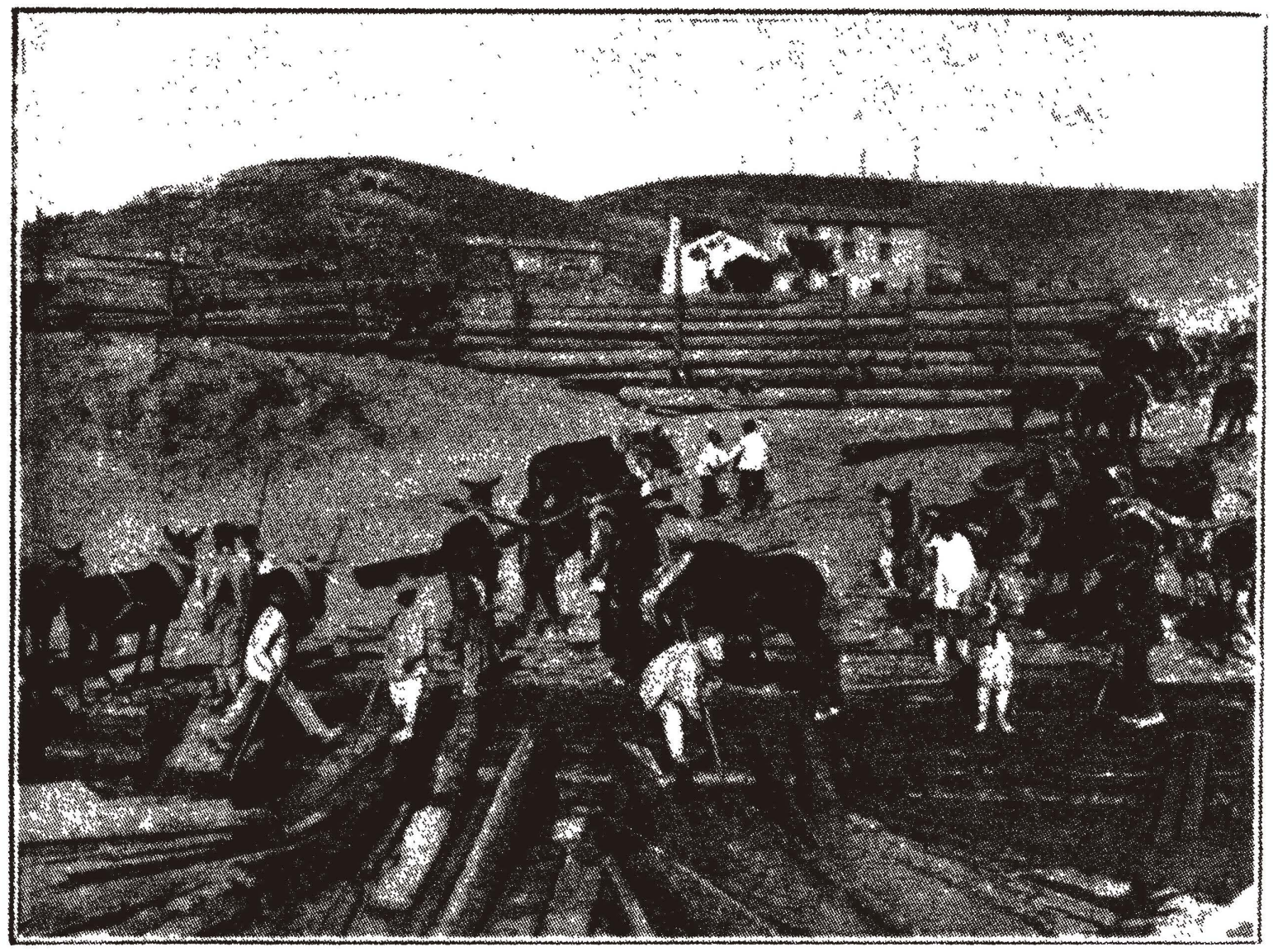

Lám. II.-Saca de la madera (de la Guia de Cuenca de Larrañaga, 1929). 